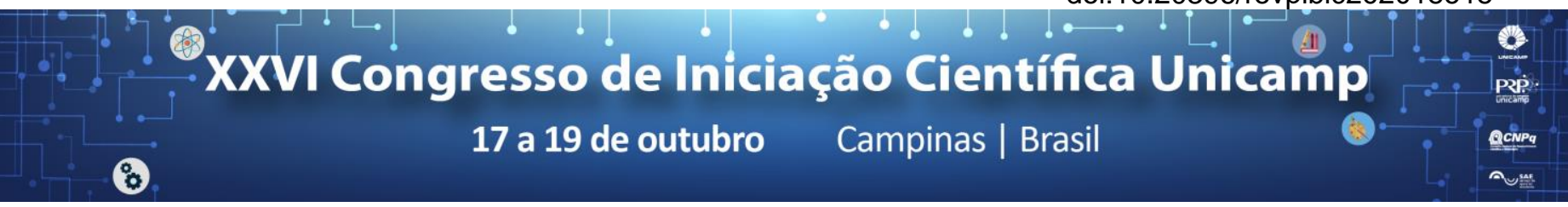

\title{
ENCAPSULAÇÃO E CARACTERIZAÇÃO DO FÁRMACO METFORMINA EM $\beta$-CICLODEXTRINA
}

\author{
Prof. Dr. Francisco B.T. Pessine, Gabriela S. Bezerra*.
}

\section{Resumo}

Tendo em vista as inúmeras reações adversas que o uso de Metformina pode trazer, sendo alguns deles, perturbações do trato gastrintestinal como náusea; vômito; diarreia e desconforto abdominal, além de mal-estar e hiperventilação. Tem-se estudado sobre a complexação deste fármaco em agentes encapsuladores que possibilitem o aumento de sua solubilidade e redução de efeitos adversos. Neste trabalho utilizou-se a $\beta$-Ciclodextrina $(\beta C D)$ como agente encapsulador em razão de sua estrutura toroidal. A cavidade interna sendo hidrofóbica possui afinidade pelas moléculas do fármaco, já sua parte externa é hidrofílica, o que levaria a um aumento na solubilidade da metformina, e com isso uma prevista diminuição nos efeitos adversos.

\section{Palavras-chave:}

Encapsulação, Metformina, $\beta$-Ciclodextrina $(\beta C D)$.

\section{Introdução}

Metformina é um fármaco usado, via administração oral como adjuvante da dieta no controle de diabetes insulino independente (tipo II) quando o regime alimentar sozinho não permite normalização do peso e/ou glicemia. $O$ fator limitante, e que compromete a eficiência terapêutica da metformina, é sua baixa solubilidade em água, sendo bastante hidrofóbica, o que também afeta sua absorção intestinal e biodisponibilidade. A complexação deste fármaco aspirando aumentar sua pequena solubilidade e reduzir efeitos adversos é uma alternativa promissora para obter formulações clinicamente mais eficientes. Ciclodextrinas são polissacarídeos cíclicos com estrutura toroidal, que possui cavidade central hidrofóbica e com tamanho adequado à encapsulação de moléculas também hidrofóbicas. Neste trabalho será feita encapsulação de Metformina (Met) em $\beta$-ciclodextrina $(\beta C D)$, usando a estratégia de co-precipitação para preparar o complexo de inclusão. Após a obtenção do complexo ele também será caracterizado físico quimicamente.

\section{Resultados e Discussão}

A coprecipitação é uma técnica que consiste na preparação de uma solução do fármaco de interesse e a ciclodextrina. As soluções foram preparadas perto do ponto de saturação e depois misturadas, sob aquecimento e agitação continua por varias horas, posteriormente submetida a uma mudança brusca de temperatura $3-5{ }^{\circ} \mathrm{C}$ (em refrigerador). ${ }^{1,2}$ Os cristais obtidos foram então separados do restante da solução por meio de filtração e secados em estufa a $50{ }^{\circ} \mathrm{C}$. Foram utilizadas técnicas de espectroscopia no infravermelho (FTIR), que é muito utilizada em determinações rápidas e bastante precisas para saber se houve realmente a formação do complexo, também foi utilizada a técnica de difração de raios-X. Quando os resultados obtidos por ambas as técnicas foram comparados com o espectro e com o difratograma de ambos os componentes do complexo em sua forma pura, notou-se que os resultados eram muito similares aos dados da $\beta$-ciclodextrina, mesmo tento um excesso de fármaco no meio em que o complexo foi formado. Os resultados então confirmaram a formação do complexo, e indicaram ainda que boa parcela do fármaco estaria dentro da cavidade da $\beta$-ciclodextrina, como 0 esperado. $2,3,4$ e 5

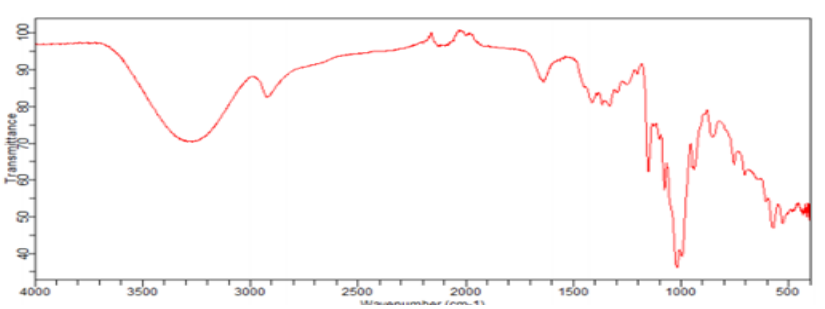

Figura 1. Espectro de infravermelho do complexo $\beta C D$ Met

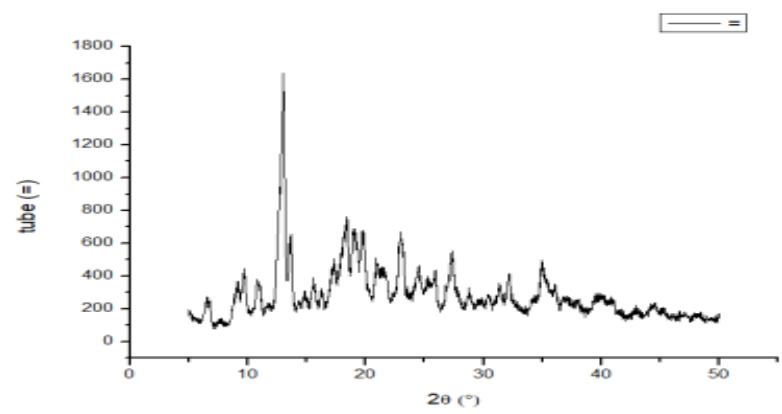

Figura 2. Difratograma obtido por difração de raios- $X$ do complexo $\beta C D-M e t$

\section{Conclusões}

Assim sendo, tem-se que a obtenção do fármaco Metformina em $\beta$-ciclodextrina em forma de complexo foi realizada. Possibilitanto estudos futuros para constatar se a diminuição dos efeitos adversos, causados pela baixa solubilidade do fármaco puro foi realmente alcansada.

\section{Agradecimentos}

Agradeço ao meu orientador por toda ajuda, ao Programa Institucional de Bolsas de Iniciação em Desenvolvimento Tecnológico e Inovação pela bolsa fornecida, e também a UNICAMP por toda a infraestrutura que possibilitaram o desenvolvimento desse projeto.

1) J. Szejtli, K-L. Frömming. Cyclodextrins in Pharmacy, Kluwer Academic Publ., 1994.

2) A. Calderini. Dissertação de Mestrado-IQ/UNICAMP, 2006

3) F.J.B. Veiga, J.J. Torres-Labandeira, L. Ribeiro, A. Figueiras. J. Incl. Phenom. Macr. Chem. 57, 531 (2007)

4) S.A. Elkhershen, S. Badr-Eldin, M.M. Ghorab. Eur. J. Pharm. Biopharm. 70, 819 (2008).

5) H.A. Al-Marzouqi, B. Jobe, A. Dowaidar, F. Maestrelli, P. Mura. J. Pharm. Biomed. Anal. 43, 66 (2007). 